\title{
Involvement of Fungal Pectin Methylesterase Activity in the Interaction Between Fusarium graminearum and Wheat
}

\author{
Luca Sella, ${ }^{1}$ Carla Castiglioni, ${ }^{1}$ Maria Chiara Paccanaro, ${ }^{1}$ Michela Janni, ${ }^{2}$ Wilhelm Schäfer, ${ }^{3}$ \\ Renato D'Ovidio, ${ }^{2}$ and Francesco Favaron'
}

${ }^{1}$ Dipartimento Territorio e Sistemi Agro-Forestali (TeSAF), Research group in Plant Pathology, Università di Padova, Viale dell'Università 16, 35020 Legnaro (PD), Italy; ${ }^{2}$ Dipartimento di Scienze e tecnologie per l'Agricoltura, le Foreste, la Natura e I'Energia, (DAFNE), Università della Tuscia, Via S. Camillo de Lellis snc, 01100 Viterbo, Italy; and ${ }^{3}$ Biocenter Klein Flottbek, Molecular Phytopathology and Genetics, University of Hamburg, Hamburg Germany

Submitted 31 July 2015. Accepted 22 December 2015.

\begin{abstract}
The genome of Fusarium graminearum, the causal agent of Fusarium head blight of wheat, contains two putative pectin methylesterase (PME)-encoding genes. However, when grown in liquid culture containing pectin, $F$. graminearum produces only a single PME, which was purified and identified. Its encoding gene, expressed during wheat spike infection, was disrupted by targeted homologous recombination. Two $\Delta$ pme mutant strains lacked PME activity but were still able to grow on highly methyl-esterified pectin even though their polygalacturonase (PG) activity showed a reduced capacity to depolymerize this substrate. The enzymatic assays performed with purified $F$. graminearum $P G$ and PME demonstrated an increase in PG activity in the presence of PME on highly methyl-esterified pectin. The virulence of the mutant strains was tested on Triticum aestivum and Triticum durum spikes, and a significant reduction in the percentage of symptomatic spikelets was observed between 7 and 12 days postinfection compared with wild type, demonstrating that the $F$. graminearum PME contributes to fungal virulence on wheat by promoting spike colonization in the initial and middle stages of infection. In contrast, transgenic wheat plants with increased levels of pectin methyl esterification did not show any increase in resistance to the $\Delta$ pme mutant, indicating that the infectivity of the fungus relies only to a certain degree on pectin degradation.
\end{abstract}

Fusarium graminearum is the causal agent of the Fusarium head blight (FHB) disease, which affects wheat, barley, and other small grain cereals. FHB alters the quality, weight, and composition of kernels, causing contamination by fungal toxins such as the trichothecene deoxynivalenol (Kikot et al. 2009; McMullen et al. 1997).

The fungus is known to enter the host through natural openings (Pritsch et al. 2000) or by penetrating the epidermal cell walls directly with short infection hyphae (Wanjiru et al. 2002). Anthers are reported as the primary infection site where spores of the fungus may land and then grow into the soft ovarian tissue and the inner surfaces of the lemma and palea

Corresponding author: L. Sella; E-mail: luca.sella@unipd.it

*The $\boldsymbol{e}$-Xtra logo stands for "electronic extra" and indicates that one supplementary figure is published online.

() 2016 The American Phytopathological Society
(Goswami and Kistler 2004) before spreading systemically through the spike. It is likely that $F$. graminearum penetrates and colonizes these host tissues via the activity of secreted cell wall-degrading enzymes (Kang and Buchenauer 2000a and b; Wanjiru et al. 2002).

Among cell wall-degrading enzymes, pectinolytic enzymes are the first degrading enzymes to be induced when $F$. graminearum is grown on plant cell walls and the first produced in infected tissues (Kikot et al. 2009). Pectins are mainly composed of two types of polymers: i) homogalacturonan, consisting of $\alpha 1-4$ linked D-galacturonic acid residues that may be variably methylesterified on the carboxylic group, and ii) rhamnogalacturonan, mainly consisting of an L-rhamnose and D-galacturonic acid repeat in which the rhamnose residues carry some neutral side chains of either arabinose, galactose, or both. Among the pectinases, endo-PGs (polygalacturonases) (EC 3.2.1.15), which break down the partially de-esterified homogalacturonan via a hydrolytic mechanism, and pectin methylesterases (PMEs) (EC 3.1.1.11), which catalyze the de-esterification of pectins by removing the methoxy esters, can act synergistically, causing plant tissue maceration and increasing the accessibility of cellwall components for degradation by other enzymes. In particular, PGs are expressed in the early stages of host infection (Sella et al. 2005; Tomassini et al. 2009) and, by degrading the pectin component of the cell wall and middle lamella, have been shown to strongly contribute to disease symptoms caused by several fungi (Clay et al. 1997; Isshiki et al. 2001; Oeser et al. 2002; Shieh et al. 1997; ten Have et al. 1998, 2002), although other authors have ruled out an involvement of pectinolytic enzymes in pathogenicity (Di Pietro and Roncero 1998; Gao et al. 1996; Scott-Craig et al. 1998).

Fungal pectinases are also important during the infection of cereal plants (Oeser et al. 2002; Wanjiru et al. 2002), although Poaceae contain a low level of pectin in their cell wall (Vogel 2008). Indeed, homogalacturonan and methyl-esterified homogalacturonan are abundant constituents of ovary cell walls in grasses such as rye (Tenberge et al. 1996), and methyl-esterified homogalacturonan has been found in the pericarp of wheat ovaries at the anthesis stage (Chateigner-Boutin et al. 2014). Additionally, at the initial stage of infection, $F$. graminearum producing PG activity affects the wheat ovary (Miller et al. 2004; Tomassini et al. 2009). As indirect evidence of the involvement of $\mathrm{PG}$ activity during $F$. graminearum wheat infection, the expression of a bean polygalacturonase-inhibiting protein (PvPGIP2) in transgenic wheat plants limits the disease 
symptom development caused by this pathogen (Ferrari et al. 2012). Since the PG hydrolyzes mostly de-esterified pectin (homogalacturonan), a PME activity that is able to demethylate wheat pectins is likely involved at the early stage of fungal infection.

PME is a virulence factor of the polyphagous necrotrophic fungus Botrytis cinerea, and the knockout of one of the two pme genes (Bcpme1), responsible for $75 \%$ of the fungal PME activity, caused a reduction in the fungal virulence on tissues of several host plants, such as apple fruits and leaves of grapevine and Arabidopsis thaliana (Valette-Collet et al. 2003). However, other authors (Kars et al. 2005) produced B. cinerea knockout mutants lacking both Bcpme genes (including Bcpme1) and their growth on highly methylated pectin was not affected, nor did they show a reduction in virulence. These conflicting results may be a consequence of different $B$. cinerea strains used in the gene disruption experiments (Kars et al. 2005).

Recently, transgenic durum wheat lines expressing high levels of the PME inhibitor of Actinidia chinensis (AcPMEI) showed an increased degree of methyl-esterification of cellwall pectins and a significant reduction of disease symptoms caused by $F$. graminearum and Bipolaris sorokiniana (Volpi et al. 2011). Methyl-esterification levels of wheat cell-wall pectin appear, therefore, to influence plant resistance, because highly methyl-esterified pectin is less vulnerable to pectic enzyme degradation.

Using an in silico analysis of the $F$. graminearum sequenced genome, available online from the Institute of Bioinformatics and Systems Biology database and the Fusarium Comparative database, two putative PME-encoding genes have been identified. The gene FGSG_03406 has a nucleotide sequence of $1,077 \mathrm{bp}$, which corresponds to a transcript of $981 \mathrm{bp}$ and a deduced protein of 326 amino acids, including a secretion signal peptide. This PME has a typical single pectin esterase domain and shows a very high identity with several PMEs from other fungal species belonging to genera Fusarium, Verticillium, Colletotrichum, Neonectria, and Diaporthe. The gene FGSG_04439 is much more complex, with a nucleotide sequence of $7,767 \mathrm{bp}$, a hypothetical transcript of 7,557 bp, and a deduced protein of 2,518 amino acids, including the secretory signal peptide. Unlike the protein encoded by the FGSG_03406 gene, the FGSG_04439 protein shows homology only with a few fungal putative PMEs of species belonging to the Fusarium genus. The size of this hypothetical protein is due to the presence of four putative pectinesterase domains.

Two recent transcriptomic studies (Güldener et al. 2006; Lysøe et al. 2011) seem to indicate that both genes are expressed by $F$. graminearum during barley and wheat spike infections, although the FGSG_03406 transcript appears to be expressed earlier in the infected tissue (48 to $72 \mathrm{~h}$ postinfection [hpi]). However, in a comparative proteomic study, only the FGSG_03406 protein was detected in the secretome of $F$. graminearum grown on pectin or plant cell walls (Paper et al. 2007).

The main objective of the present work was to clarify the importance of the $F$. graminearum PME activity during FHB of wheat. Thus, we first characterized the PME activity produced by the fungus, and then, we produced a $F$. graminearum $\Delta$ pme knockout mutant and tested its virulence on wheat spikes (Triticum aestivum and Triticum durum) and on transgenic AcPMEI wheat plants possessing an increased level of cell-wall pectin methyl-esterification.

The secondary objective was to determine if the contribution of the F. graminearum PME is to favor pectin degradation by the fungal PG activity. To this end, we verified the capability of the $\Delta$ pme mutant to efficiently degrade pectins having different degrees of methyl-esterification, and we checked if the purified $F$. graminearum $\mathrm{PME}$ enhances the activity of the fungal $\mathrm{PG}$ (namely PG1) (Tomassini et al. 2009) on pectins having different esterification levels.

\section{RESULTS}

Production and purification of $\boldsymbol{F}$. graminearum PME.

To obtain PME activity, $F$. graminearum was grown for 5 days in liquid culture medium containing pectin as the sole carbon source. The culture filtrate was then concentrated and analyzed by analytical isoelectric focusing (IEF) and, after a pectin gel blot assay, a single protein band with a basic isoelectric point (pI) of approximately 9.2 was visualized (data not shown).

The $F$. graminearum PME was purified by preparative IEF. Because the $\mathrm{pI}$ of this PME is very close to that of a $F$. graminearum $\mathrm{PG}$, to avoid contamination, we purified the PME from the two most active fractions above $\mathrm{pH}$ 9.7, which were pooled and further purified by cation-exchange chromatography (MonoS-column). Two aliquots of the most active MonoS fraction were loaded onto a polyacrylamide (PAA) gel and were subjected to analytical IEF. After the run, a lane of the gel was stained with Coomassie brilliant blue and another lane was developed for PME activity, using a pectin gel blot assay. A unique protein band with $\mathrm{pI} 9.2$ was evidenced in the PAA gel, and a broad PME band was detected on the pectin gel at the same pI (Fig. 1). After trypsin digestion, this protein band was analyzed by liquid chromatography-tandem mass spectrometry (LC-MS/MS). The five peptides obtained (Table 1) corresponded to the putative pectinesterase precursor protein deduced from the FGSG_03406 gene.

\section{FgPme1 gene expression in planta.}

The expression of the gene encoding FGSG_03406 PME (hereafter, $\mathrm{FgPme1}$ ) was analyzed by real-time polymerase

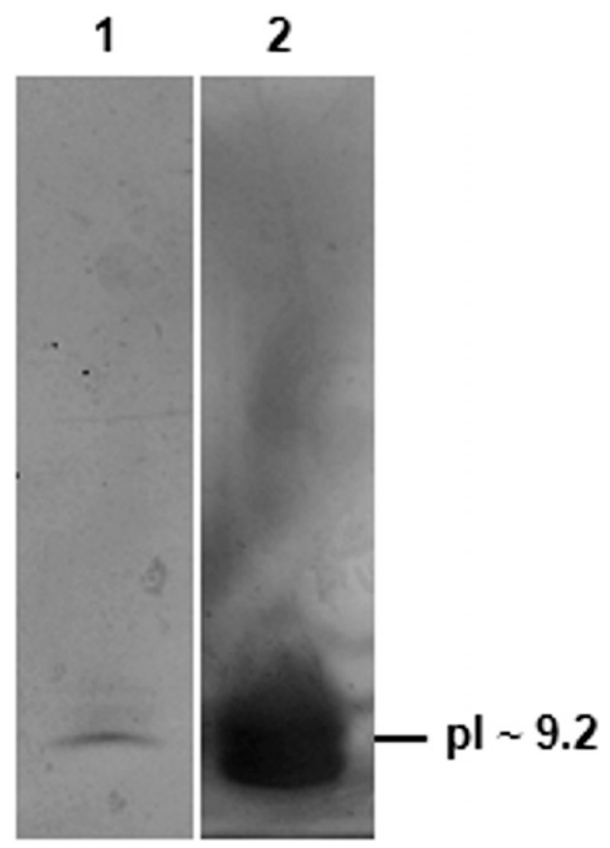

Fig. 1. Thin-layer isoelectric focusing (IEF) in the $\mathrm{pH}$ range 8.0 to 10.5 of the most active MonoS fraction. The sample was loaded onto two different lanes of a polyacrylamide gel. After focusing, one section of the gel (lane 1) was stained with Coomassie brilliant blue, the other (lane 2) was overlaid on an agarose gel containing pectin and was stained with ruthenium red. A single pectin methylesterase band with a basic isoelectric point (pI) of approximately 9.2 was visualized, was excised from the gel, and was subjected to digestion for identification by liquid chromatography-tandem mass spectrometry. 
chain reaction (PCR) using RNA extracted from infected wheat spikelets at $0,1,2,3$, and 4 days postinfection (dpi) with $F$. graminearum. The fungal $\beta$-tubulin was the reference gene.

A relative expression analysis showed that the $\mathrm{FgPmel}$ transcript is already present in infected wheat spikelets at $1 \mathrm{dpi}$ and accumulates at similar levels at 3 and 4 dpi (Fig. 2) but was not detected in mock-inoculated spikelets.

\section{Knockout of the $\mathrm{F}$. graminearum $\mathrm{FgPme1}$ gene.}

The $F$. graminearum wild-type (WT) strain was transformed with the pGEM- $\triangle \mathrm{PME}$ construct to obtain a targeted disruption of the FgPmel gene via integration of the hygromycinresistance gene. Two independent transformation experiments were performed. In the first transformation, nine $F$. graminearum transformants were obtained, and after PCR screening, only three transformants did not produce the expected Pme amplicon (data not shown). After a single conidiation, these transformants were analyzed using a high-stringency Southern blot. Only one $\Delta$ pme mutant strain ( $\Delta$ pme1.1) showed the absence of the 1.8-kb fragment corresponding to the FgPmel gene (Fig. 3, lane 1$)$. Hybridization of this strain $(\Delta$ pme 1.1$)$ with the hygromycin probe showed the expected $3.3-\mathrm{kb}$ band corresponding to the homologous recombination of the disruption construct and a second band corresponding to the ectopic integration of the hygromycin cassette (Fig. 3, lane 7).

The second transformation produced $30 \mathrm{~F}$. graminearum transformants resistant to hygromycin. A PCR analysis showed the lack of the FgPmel gene in only four transformants (data not shown). After a single conidiation, these four transformants were analyzed using a high-stringency Southern blot and all of the mutant strains showed the absence of the $1.8-\mathrm{kb}$ band corresponding to the $\mathrm{FgPme} 1$ gene (Fig. 3, lanes 2 to 5). However, only one of these $(\Delta$ pme 1.2$)$ showed a single homologous integration of the hygromycin cassette (Fig. 3, lane 9).

\section{In vitro characterization of the $\Delta$ pme mutant strains.}

To verify whether the $F g P m e 1$ gene deletion impaired mycelial growth, the selected $\Delta$ pme 1.1 and $\Delta$ pme1.2 strains were transferred to potato dextrose agar (PDA) and synthetic nutrient agar (SNA) plates. In both media, no difference in growth was observed between the WT and the mutant strains. Additionally, the conidial production of the mutant strains in carboxymethyl cellulose liquid culture or in SNA plates appeared similar to that of WT (data not shown).

A $\Delta$ pme mutant and the WT strain were also grown on a liquid culture medium containing pectin (72\% methyl esterification) as the sole carbon source. After 4 days, aliquots of these cultures were run in a PAA gel and, after IEF, the PME activity was detected using a pectin gel blot assay. The $\Delta$ pme mutant culture did not show any PME bands, while the WT culture showed the expected basic PME band (with a deduced pI of approximately 9.2) (Fig. 4). Weak but clear bands corresponding to $\mathrm{PG}$ isoforms were also present in both samples. These results confirmed the success of the gene knockout and that the FGSG_03406 gene encodes for the PME enzyme.

We also determined the amount of mycelium produced by WT and mutant strains by measuring the dry weight after 4 days of growth in liquid culture with pectin (72\% methyl esterification) as the sole carbon source. No significant difference was observed between the strains tested (Fig. 5), and the same result was obtained using a liquid culture containing $38 \%$ esterified pectin (data not shown).

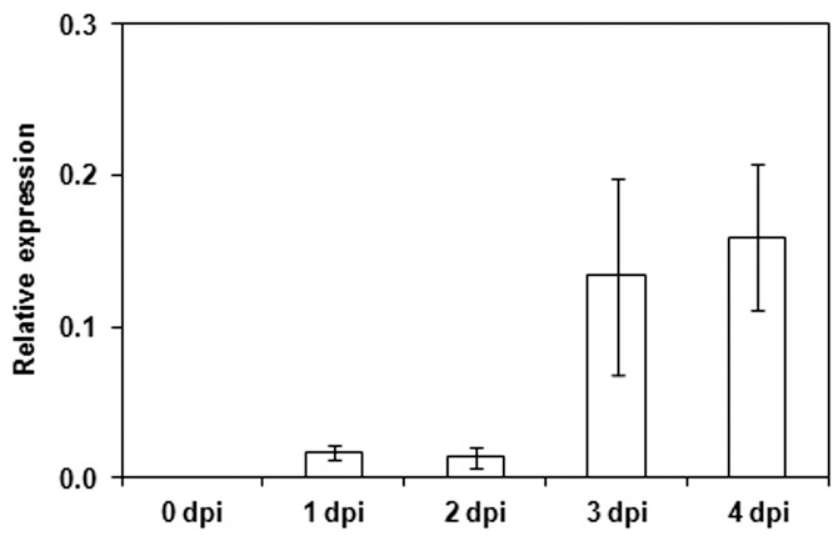

Fig. 2. Relative expression level of the Fusarium graminearum FgPme1 gene at $0,1,2,3$, and 4 days after wheat spike infection (dpi). The $F$. graminearum $\beta$-tubulin gene was used as a reference gene. Data represent the average \pm mean standard error of the relative expression of at least four independent quantitative polymerase chain reaction experiments.

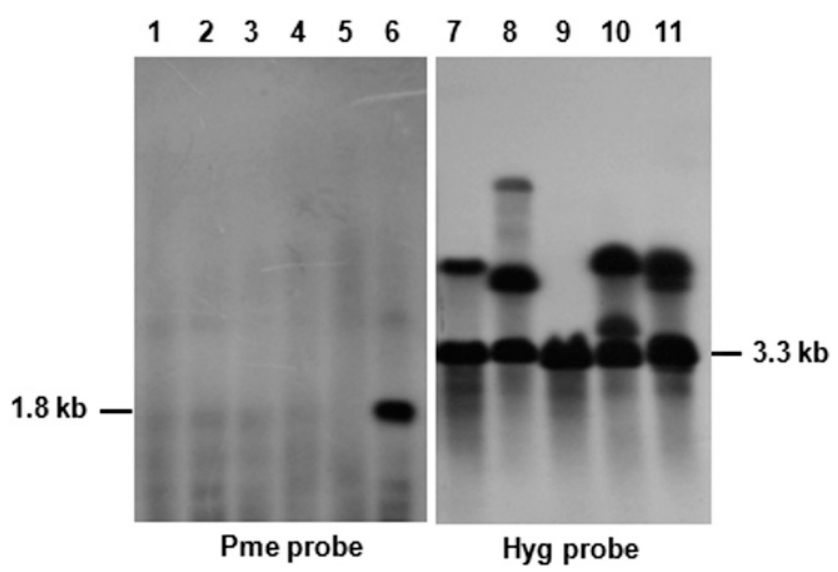

Fig. 3. High-stringency Southern blot analysis of Fusarium graminearum wild type (WT) and mutant strain genomic DNA digested with ClaI. Lanes 1 to 6, A fragment of the $\mathrm{FgPmel}$ gene was used as a specific probe. Only the WT strain (lane 6) showed a hybridization signal of approximately $1.8 \mathrm{~kb}$, corresponding to the FgPmel gene. The $\Delta$ pme mutant strains $\Delta$ pme1.1 (lane 1) from the first fungal transformation and $\Delta$ pme1.2, $\Delta$ pme1.3, $\Delta$ pme1.4, and $\Delta$ pme1.5 (lanes 2 to 5 , respectively) from the second fungal transformation did not show the hybridization signal corresponding to the FgPmel gene. Lanes 7 to 11, A fragment of the hph gene was used as a specific probe. The $\Delta$ pme mutant strain from the first fungal transformation ( $\Delta$ pme1.1, lane 7 ) showed the expected 3.3-kb band corresponding to the homologous recombination of the disruption construct and a second ectopic integration. Among the $\Delta$ pme mutant strains from the second fungal transformation, only $\Delta$ pme1.2 (lane 9) showed a single homologous integration of the hygromycin cassette at $3.3 \mathrm{~kb}$, while $\Delta$ pme1.3, $\Delta$ pme 1.4, and $\Delta$ pme 1.5 (lanes 8,10 , and 11, respectively) showed one or two ectopic hybridization signals.

Table 1. Liquid chromatography-tandem mass spectrometry analysis of the excised protein band with pectin methylesterase (PME) activity

\begin{tabular}{|c|c|c|c|c|c|}
\hline Observed & $\operatorname{Mr}(\operatorname{expt})$ & Mr(calc) & Ppm & Score & Peptide \\
\hline $1,393.80$ & $1,392.79$ & $1,392.74$ & 42.2 & 57 & R.VVSASVGYITANGR.D \\
\hline $1,532.79$ & $1,531.78$ & $1,531.72$ & 38.6 & 57 & K.SQADGLNNDGTATLR.V \\
\hline $1,602.79$ & $1,601.78$ & $1,601.73$ & 32.1 & 93 & K.CMIAGATDFIFGQR.A + Oxidation (M) \\
\hline $2,138.07$ & $2,137.06$ & $2,137.00$ & 31.9 & 156 & R.NAQLTIYGYTTDTSGYAGNK.V \\
\hline $2,410.16$ & $2,409.15$ & $2,409.06$ & 37.6 & 65 & K.GEENTGHVQFSEFGNTGAGSTGAR.A \\
\hline
\end{tabular}


To test the ability of WT and $\Delta$ pme mutant strains to degrade highly methylated pectin, aliquots of the culture filtrates were adjusted to contain the same PG activity as determined on polygalacturonic acid (PGA) and were assayed on pectins with 38 and $72 \%$ degrees of methyl-esterification. After a prolonged incubation time $(24 \mathrm{~h})$, the culture filtrates of the two $\Delta$ pme mutant strains had hydrolysis values comparable to those of the WT culture filtrate on PGA and $38 \%$ esterified pectin, while on the $72 \%$ esterified pectin, the hydrolysis percentage of the two $\Delta$ pme mutant strains was approximately 2.5 -fold lower than that of the WT (Fig. 6).

\section{Complementation of the $\Delta$ pme mutant.}

The $\Delta$ pme mutant was complemented by the introduction of the entire pme gene flanked by the native promoter and terminator sequences into the $\Delta$ pme1.2 strain. The transformants obtained were screened by PCR (data not shown), and Southern blot analysis (Supplementary Fig. 1) confirmed the presence of the pme gene in three strains. An IEF analysis confirmed the restoration of the PME activity in the Pme2.8C strain (Fig. 4). The culture filtrate of this strain also showed an activity comparable to that of the WT culture filtrate on PGA and pectins (Fig. 6).

\section{Infection of T. aestivum wheat plants.}

Wheat spikes of T. aestivum were point-inoculated at anthesis with a spore suspension of WT, $\Delta$ pme1.1, and $\Delta$ pme1.2

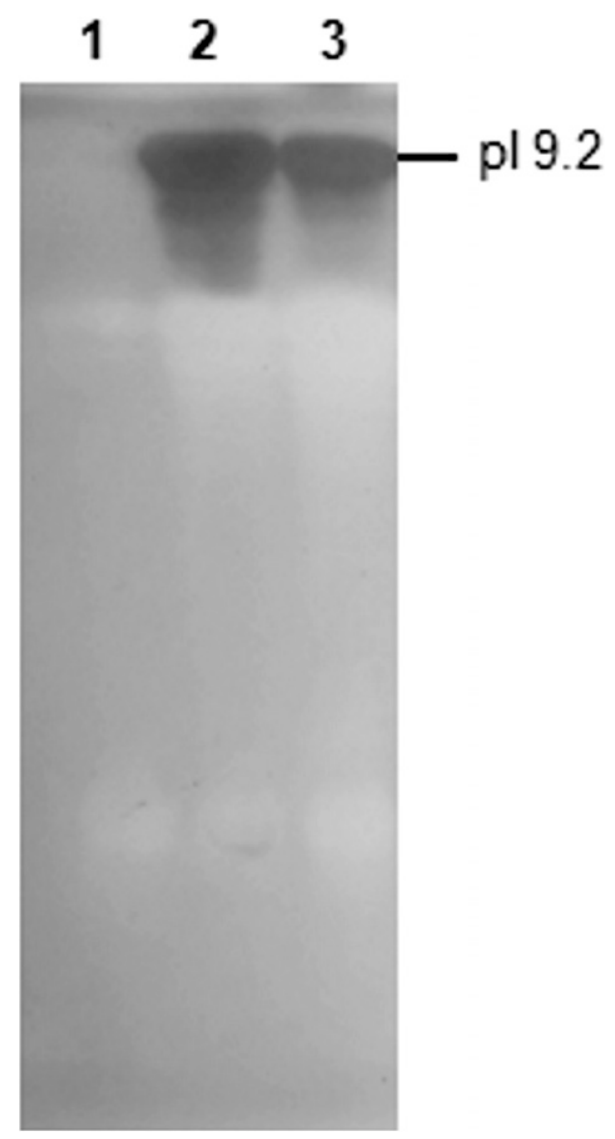

Fig. 4. Thin-layer isoelectric focusing (IEF) in the $\mathrm{pH}$ range 3 to 10 of the pectin methylesterase (PME) activity produced by Fusarium graminearum wild type (WT) (lane 2), $\Delta$ pme1.2 mutant (lane 1), and Pme2.8C complemented strain (lane 3 ) in liquid culture containing pectin as the sole carbon source. An equal volume $(20 \mu \mathrm{l})$ of 4 -day-old liquid culture was loaded on the polyacrylamide (PAA) gel. After focusing, the PAA gel was blotted on an agarose overlay gel containing pectin (methylesterification degree $72 \%$ ) buffered at $\mathrm{pH}$ 6.0, and the PME isoform was detected by ruthenium red staining. The isoelectric point of the F. graminearum PME (9.2) is reported on the right. strains, and symptom development was assessed up to $21 \mathrm{dpi}$. The knockout mutant strains maintained the capability to infect wheat plants. However, between 7 and 12 dpi, symptoms caused by the mutant strains were significantly reduced compared with those in the WT (Fig. 7). In particular, infection with the $\Delta$ pme1.1 and $\Delta$ pme1.2 strains showed a significant 20 to $25 \%$ reduction of symptomatic spikelets in comparison with the WT (Fig. 7). At later stages, the differences between the $\Delta$ pme strains and the WT were not significant.

Infection experiments were also repeated with the complemented strain. The virulence of the Pme2.8C strain was comparable to that of the WT strain, and both had 25 to $30 \%$ more symptomatic spikelets between 10 and 14 dpi in comparison with the $\Delta$ pme mutant (Fig. 8).

\section{Infection of transgenic durum wheat plants having higher methyl-esterified cell walls.}

The transgenic MJ15-69 line (69T) of T. durum constitutively expresses AcPMEI and has a higher level of methyl esterification of cell-wall pectin (about 50\% esterification degree) (Volpi et al. 2011), in comparison with the WT untransformed cv. Svevo or the transformed null segregant line MJ15-69NS (69NS), which have pectins that are approximately $20 \%$ methyl esterified (Volpi et al. 2011; data not published). It was previously reported that the MJ15-69 line was more resistant to F. graminearum in comparison with the MJ15-69NS line (Volpi et al. 2011). To establish whether the contemporary presence of higher methyl-esterification levels of pectin cell walls in wheat and the absence of PME activity in F. graminearum can affect the outcome of the disease, plants of the MJ15-69NS and MJ15-69 lines were point-inoculated at anthesis with a suspension of spores of WT or $\Delta$ pme1.1 strains and symptoms were assessed up to 18 dpi.

The $\Delta$ pme1.1 mutant caused less severe symptoms compared with the WT strain on the T. durum MJ15-69NS line, with approximately 25 to $40 \%$ fewer symptomatic spikelets between 7 and 10 dpi (Fig. 9) while, at later stages, this difference decreased to only $10 \%$ and was not significant. On transgenic MJ15-69 plants, at every time point, the $\Delta$ pme 1.1 showed infection rates similar to those of the WT strain, with

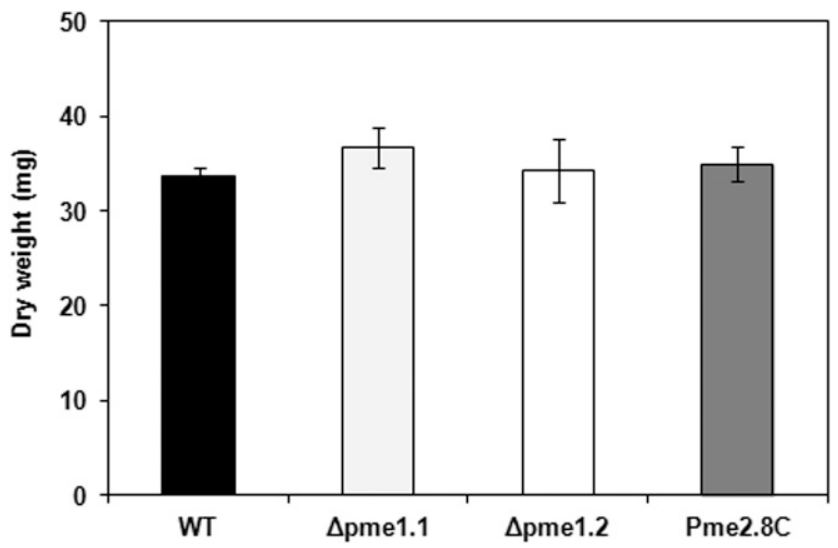

Fig. 5. Dry weight $(\mathrm{mg})$ of wild type (WT), $\Delta$ pme mutant, and complemented strains grown for 4 days in liquid culture containing pectin (methylesterification degree $72 \%$ ) as the sole carbon source. Conidia of Fusarium graminearum WT, mutant, and complemented strains $\left(1 \times 10^{4}\right.$ conidia per milliliter) were grown in $25 \mathrm{ml}$ of Szècsi liquid medium supplemented with $0.5 \%$ (wt/vol) pectin at $100 \mathrm{rpm}$ and $25^{\circ} \mathrm{C}$. Data represent the average \pm standard error (indicated by bars) of two independent experiments. Data were statistically analyzed by applying the Tukey-Kramer's test. WT $=F$. graminearum wild-type strain; $\Delta$ pme1.1 and $\Delta$ pme $1.2=\Delta$ pme mutant strains; Pme2.8C = complemented strain. 
about 35 to $45 \%$ fewer symptomatic spikelets between 7 and 10 dpi compared with null segregant plants (Fig. 9). At later stages, these differences decreased to only $10 \%$.

\section{PME affects PG activity on pectin.}

To understand how much the $F$. graminearum PME affects the activity of the fungal PG on pectin, the purified PME was mixed with the main $F$. graminearum $\mathrm{PG}$ isoform (PG1) and the activity of the mixture was assayed on pectins with different degrees of methyl esterification $(8,38$, and $72 \%)$. The PG activity was determined viscosimetrically. On $8 \%$ esterified pectin, the presence of the PME did not change the PG activity; however, on $38 \%$ esterified pectin, the presence of PME increased the PG activity slightly but significantly (approximately $8 \%$ ) (Table 2). On $72 \%$ esterified pectin, the presence of PME was crucial for the PG viscosimetric activity because, in the absence of PME, the PG was unable to halve the initial relative viscosity of the substrate (Table 2). As expected, PME alone was unable to significantly decrease the viscosity of the three substrates.

\section{DISCUSSION}

The degree and pattern of methyl-esterification of plant cellwall pectin components influences the plant's susceptibility to pathogens (Malinovsky et al. 2014). Fungal PMEs, by de-methyl esterifying pectin, are considered to favor pectin degradation by other pectinolytic enzymes, such as PGs and pectate lyases (PLs). Indeed, the activity levels of the latter enzymes decreases with an increase in the level of pectin methyl esterification (Kikot et al. 2009; Valette-Collet et al. 2003).

While several PG or PL enzymes of some pathogenic fungi are necessary for infection or for contributing to disease symptoms, to date, only the PME of the fungal pathogen $B$. cinerea has been investigated as a virulence factor (Kars et al. 2005; Valette-Collet et al. 2003).

Even though pectin is less abundant in the cell walls of wheat plants than in dicots or in noncommelinoid monocots (Vogel 2008), its methyl-esterification degree and pattern affect the resistance to rust infections (Wiethölter et al. 2003) and the increased level of methyl-esterification due to expression of a plant PME inhibitor (PMEI) reduces the development of disease symptoms caused by $F$. graminearum and Bipolaris sorokiniana (Volpi et al. 2011). These results suggest that fungal PME might play a role during wheat infection.

In pectin-containing medium, $F$. graminearum produces only a single basic PME, encoded by the FgPmel gene, which is expressed in infected spikelets mostly at 3 to $4 \mathrm{dpi}$, when the disease symptoms become visible.

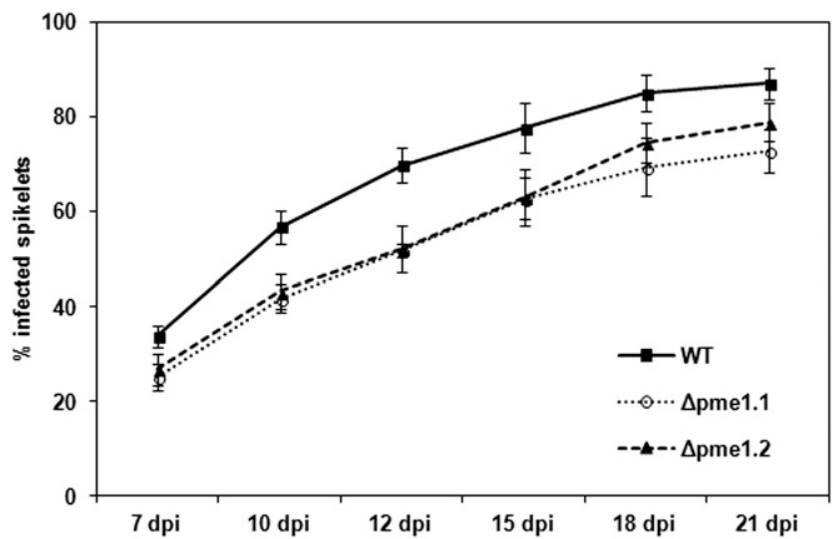

Fig. 7. Infection of Triticum aestivum (cv. Bobwhite) spikelets with Fusarium graminearum wild type (WT) and $\Delta$ pme mutant strains. To infect two florets of two opposite spikelets, $10 \mu \mathrm{l}$ of conidial suspensions (containing approximately 2,000 conidia) of WT and $\Delta$ pme 1.1 and $\Delta$ pme1.2 mutant strains were used. Infected spikelets are expressed as the percentage of symptomatic spikelets from the total number of spikelets of the respective head. Symptoms were assessed up to 21 days postinfection (dpi). Data represent the average \pm mean standard error (indicated by bars) of at least four independent infection experiments performed by inoculating at least 10 plants in each independent experiment. Average values of spikelets infected with $\Delta$ pme1.1 and $\Delta$ pme 1.2 are significantly different from WT, according to Student's $t$ test $(P \leq 0.01$ or 0.05$)$ at 7,10 , and $12 \mathrm{dpi}$.

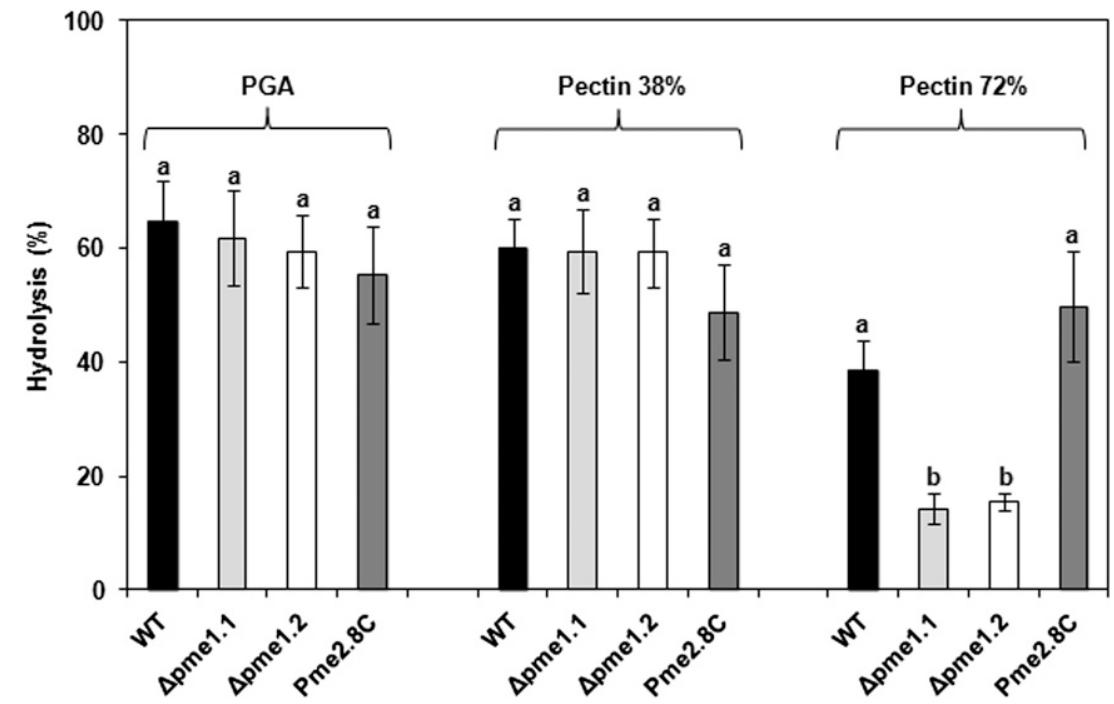

Fig. 6. Percentage of hydrolysis of polygalacturonic acid (PGA) and highly methyl-esterified apple pectins (Pectin $38 \%$ and Pectin $72 \%$ ) determined after a prolonged incubation time $(24 \mathrm{~h})$ with aliquots of culture filtrates of wild type (WT), $\Delta$ pme mutant, and complemented strains. Aliquots of culture filtrates containing an equal amount of PG activity $\left(0.005 \mathrm{RU}\right.$ ) were incubated with $0.1 \%$ (wt/vol) PGA or $0.1 \%$ (wt/vol) apple pectin $38 \%$ or pectin $72 \%$ at $30^{\circ} \mathrm{C}$ and $\mathrm{pH}$ 6.0. After $24 \mathrm{~h}$, reducing-end groups were measured and the hydrolysis percentage of each substrate was calculated. Data represent the percentage of hydrolysis \pm mean standard error (indicated by bars) of at least three independent experiments. Data were statistically analyzed by applying the TukeyKramer's test. Different letters indicate significant differences at $P<0.05$. WT $=$ Fusarium graminearum wild-type strain; $\Delta$ pme 1.1 and $\Delta$ pme $1.2=\Delta$ pme mutant strains; Pme2.8C = complemented strain. 
The FgPme1 gene was successfully disrupted by homologous recombination, and two mutant strains were characterized. When the mutant strains were assayed for virulence on $T$. aestivum and $T$. durum, a significant reduction in symptomatic spikelets was observed between 7 and $12 \mathrm{dpi}$. Later, the difference with WT decreased, becoming nonsignificant. This result and the restoring of full virulence when a mutant strain was complemented with the pme gene confirmed that the $F$. graminearum PME is necessary to support the rate of wheat spike infection.

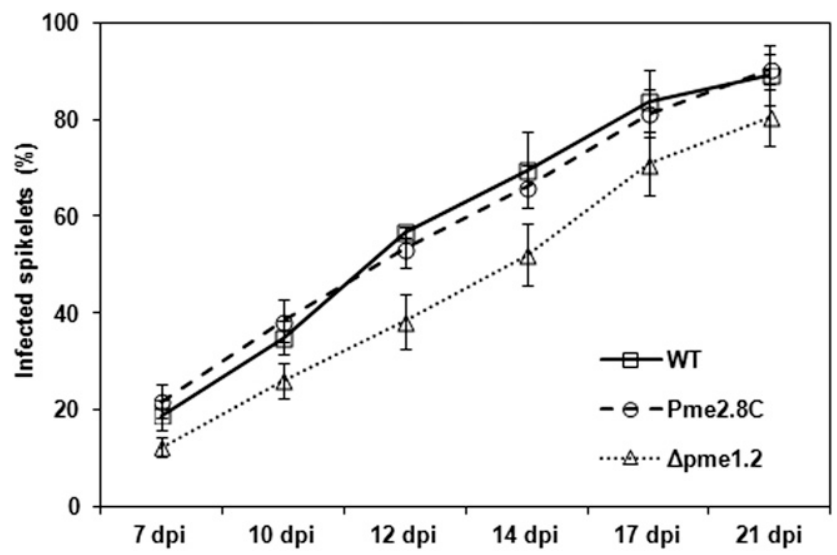

Fig. 8. Infection of Triticum aestivum (cv. Bobwhite) spikelets with Fusarium graminearum wild type (WT), $\Delta$ pme1.2 mutant, and Pme2.8C complemented strain. To infect two florets of two opposite spikelets, $10 \mu \mathrm{l}$ of conidial suspensions (containing approximately 2,000 conidia) of WT and $\Delta$ pme1.2 and Pme2.8C strains were used. Infected spikelets are expressed as the percentage of symptomatic spikelets from the total number of spikelets of the respective head. Symptoms were assessed up to 21 days postinfection (dpi). Data represent the average \pm mean standard error (indicated by bars) of at least four independent infection experiments performed by inoculating at least 10 plants in each independent experiment. Average values of infected spikelets of $\Delta$ pme 1.2 are significantly different from Pme2.8C and WT according to Student's $t$ test $(P \leq 0.01$ or 0.05$)$ at 10,12 , and 14 dpi.

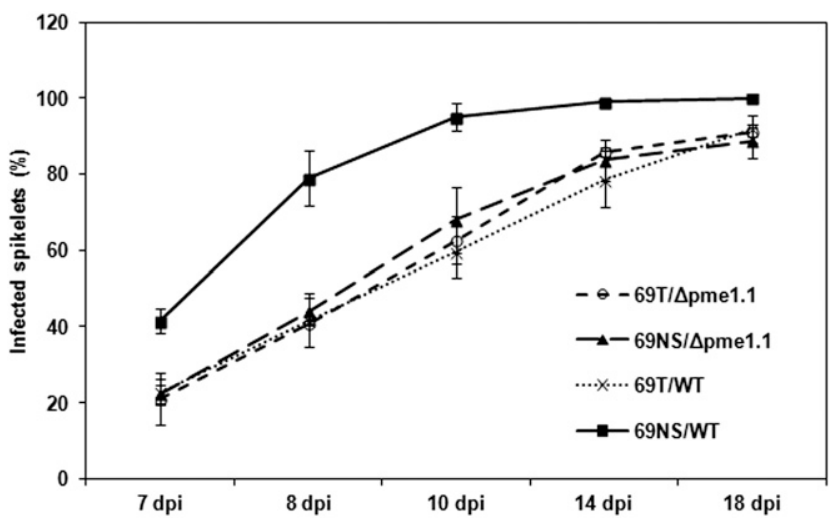

Fig. 9. Infection of spikelets of Triticum durum (cv. Svevo) MJ15-69 transgenic (69T) and MJ15-69NS null segregant (69NS) lines with Fusarium graminearum wild type (WT) and a $\Delta$ pme mutant strain $(\Delta$ pme 1.1$)$. To infect two florets of two opposite spikelets, $10 \mu \mathrm{l}$ of conidial suspension (containing approximately 500 conidia) of WT and $\Delta$ pme 1.1 mutant strains were used. Infected spikelets are expressed as the percentage of symptomatic spikelets from the total number of spikelets of the respective head. Symptoms were assessed up to 18 days postinfection (dpi). Data represent the average \pm mean standard error (indicated by bars) of three independent infection experiments performed by inoculating at least 10 plants in each independent experiment. Data were statistically analyzed by applying the Tukey-Kramer's test. Average values of MJ15-69NS spikelets infected with WT (69NS/WT) are significantly different from 69T/WT, 69NS/ $\Delta \mathrm{pme} 1.1$, and $69 \mathrm{~T} / \Delta \mathrm{pme} 1.1$ at 7,8 , and 10 dpi $(P<0.05)$.
Whether fungal PME supports infection by de-esterifying pectin and increasing the activity of fungal PGs or PLs is not obvious from our results. In fact, the enhancing effect of PME on PG activity is clearly visible in in vitro assays with highly esterified pectin and is less or not at all evident on pectin with lower degrees of methylesterification (i.e., 38 and $8 \%$ ). The average degree of pectin methyl esterification measured on leaf wheat cell walls (approximately 20\%) (Volpi et al. 2011) is not very high and was confirmed on cell walls extracted from wheat glumes (data not published). With this level of methyl esterification, the question of how the fungal PME could play, in planta, a significant role in favoring pectin degradation and, as a consequence, fungal infection remains open. However, the wheat cell wall is much more complex than the pectic substrates used in the in vitro assays and the level of methyl esterification may be different within a plant tissue depending on the developmental stage. For example, in a recent study using immunolabeling experiments, Chateigner-Boutin et al. (2014) showed that the methylation level of homogalacturonan present in the pericarp of T. aestivum varies during grain formation.

The behavior observed on the transgenic AcPMEI durum wheat plants is also worth mentioning. In these plants, the inhibition of the endogenous PME activity increases the average level of pectin methyl esterification to approximately $50 \%$ (Volpi et al. 2011) and the symptom severity caused by inoculation with the WT or $\Delta$ pme mutant strain was the same or similar to that produced by $\Delta$ pme on untransformed control plants. Thus, the combined actions of inhibiting the endogenous plant PME activity by AcPMEI expression and of eliminating fungal PME activity by gene disruption did not provide any appreciable additive effect on the reduction of symptoms. Although fungal and plant PMEs may have different modes of action, with plant PMEs suggested to remove methyl groups in a processive, block-wise fashion and fungal PMEs in a more random fashion (Jolie et al. 2010), it seems that the impairment of both these activities contributes only to a certain extent to a delay in infection. It cannot, however, be ruled out that pectin lyase (PNL) activity, which acts on esterified pectins, can partially substitute for the combined action of PME and PG or PL. Indeed, three $p n l$ genes are present in the $F$. graminearum genome and at least one of them is expressed during wheat spike infection (Lysøe et al. 2011; Paper et al. 2007; Tomassini et al. 2009). Additionally, we observed that the growth of the $\Delta$ pme mutant strains in an artificial medium containing highly methyl-esterified pectin was not impaired. This result could be explained by the presence of other carbon sources that are usually contained in commercial pectin preparations but also by the PNL activity that we detected at a low level in the artificial medium (data not shown).

In conclusion, the $F$. graminearum PME contributes to fungal virulence on wheat by promoting wheat spike infection. Nevertheless, its role seems limited to the initial and middle stages

Table 2. Viscosimetric assays of polygalacturonase (PG) activity on pectins (PECT) having different degrees of methyl-esterification $(8,38$, and $72 \%$ ) in the presence or absence of pectin methylesterase (PME)

\begin{tabular}{lccc}
\hline Enzyme & PECT 8\% & PECT 38\% & PECT 72\% \\
\hline PG & $3,894 \pm 40^{\mathrm{a}}$ & $5,626 \pm 238$ & $\infty^{\mathrm{b}}$ \\
PG + PME & $3,864 \pm 82$ & $5,167 \pm 190$ & $9,078 \pm 1515$ \\
PME & $\infty$ & $\infty$ & $\infty$ \\
\hline
\end{tabular}

${ }^{\text {a }}$ Viscosimetric activity $\left(\mathrm{T}_{50}\right)$ is expressed as the time (in seconds) required by $\mathrm{PG}$ to decrease the initial relative viscosity of the reaction mixture by $50 \%$. Each value is the mean of at least two replicates \pm standard error. Average values of PG and PG + PME on pectin $38 \%$ are significantly different, according to Student's $t$ test $(P \leq 0.05)$.

$\mathrm{b} \infty$ indicates the $\mathrm{T}_{50}$ value was not measurable (not able to decrease the initial relative viscosity by $50 \%$ ). 
of infection because symptoms development is only delayed. Later, other virulence factors, such as the mycotoxin deoxynivalenol (Bai et al. 2002), may become the predominant factor favoring pathogen spread.

\section{MATERIALS AND METHODS}

\section{Fungal strains and growth conditions.}

Fusarium graminearum WT strain 3827, provided by G. Vannacci (University of Pisa, Italy), and the mutant strains were cultured at $24^{\circ} \mathrm{C}$ on PDA (Difco Laboratories, Detroit).

To induce the production of PME activity, mycelial discs ( $5 \mathrm{~mm}$ diameter) were taken from the edge of actively growing colonies and were placed in 250-ml Erlenmeyer flasks (1 disc to $10 \mathrm{ml}$ of medium) containing $50 \mathrm{ml}$ of Szécsi medium (Szécsi 1990) supplemented with $1 \%$ (wt/vol) apple pectin (72\% esterified) (Sigma-Aldrich, Milano, Italy). The cultures were grown for 4 days at $24^{\circ} \mathrm{C}$ on an orbital shaker (at $100 \mathrm{rpm}$ ). The fungal liquid cultures obtained $(150 \mathrm{ml})$ were then filtered for an analysis of PME and PG activities.

Fungal growth was determined on 25-ml Szécsi medium containing $0.5 \%$ apple pectin (approximately $38 \%$ esterification [Carl Roth KG, Karlsruhe, Germany]; approximately $72 \%$ esterification [Sigma-Aldrich]) inoculated with $1 \times 10^{4}$ conidia per milliliter. After 4 days of culturing at $25^{\circ} \mathrm{C}$ on an orbital shaker at $100 \mathrm{rpm}$, the mycelia were filtered through a Wilson sieve $(40 \mu \mathrm{m})$, were washed twice with deionized water, were dried in an oven at $80^{\circ} \mathrm{C}$ for 3 days, and were weighed.

To obtain mycelia for DNA extraction, WT and mutant strains were grown in 50-ml complete medium (1\% [wt/vol] glucose, $0.05 \%$ [wt/vol] yeast extract, and $0.5 \%$ [wt/vol] yeast nitrogen base without amino acids, and ammonium sulfate) for 3 days at $150 \mathrm{rpm}$ and $24^{\circ} \mathrm{C}$.

Conidia of $F$. graminearum WT and mutant strains were obtained by culturing five mycelium discs ( $5 \mathrm{~mm}$ diameter) in $50 \mathrm{ml}$ of carboxymethyl cellulose liquid medium (Cappellini and Peterson 1965). After 5 to 7 days, the liquid cultures were filtered through a sterile gauze, and conidia were collected and were diluted to approximately $2 \times 10^{5}$ conidia per milliliter. Alternatively, $F$. graminearum WT and mutant strains were cultured on SNA agar plates (Urban et al. 2002) to induce conidiation. Conidia were recovered by scraping agar plates with a sterile glass rod, were diluted in sterile water, and were counted using a Thoma chamber.

\section{Purification of the $F$. graminearum PME.}

A $F$. graminearum culture filtrate was concentrated to a final volume of $50 \mathrm{ml}$ using the Vivaflow 200 (10,000 MWC PES) system (Sartorius, Milano, Italy) and was then diluted threefold and again concentrated. This operation was repeated twice. This material was used to purify the fungal PME by preparative IEF and MonoS ion exchange chromatography.

Preparative IEF was performed in a LKB 8100-1 column using a mixture of $1 \mathrm{ml}$ each of $\mathrm{pH} 7$ to 9 (Amersham Biosciences, Uppsala, Sweden) and 9 to 11 (Serva, Heidelberg, Germany) carrier ampholytes, and a sorbitol gradient. A $0.01 \mathrm{M}$ acetic acid solution was used at the anode and a $0.2 \mathrm{M}$ sodium hydroxide solution at the cathode. The IEF was performed at a constant $5 \mathrm{~W}$ for $48 \mathrm{~h}$. Fractions of $2 \mathrm{ml}$ were collected and assayed for $\mathrm{pH}$ and PME activity using analytical IEF. PME activity was detected in the fractions from $\mathrm{pH} 8.4$ to 11.7; however, fractions up to $\mathrm{pH} 9.7$ also contained $F$. graminearum PG2, with a pI approximately 9.1 (Tomassini et al. 2009). To avoid the presence of this PG, the PME was purified only from the two most active fractions with $\mathrm{pH}$ levels greater than 9.7. These were pooled, were dialyzed against $50 \mathrm{mM}$ sodium acetate buffer ( $\mathrm{pH}$ 5.0), and were loaded on a MonoS HR 5/5 column (GE Healthcare, Uppsala, Sweden) equilibrated with $50 \mathrm{mM}$ sodium acetate buffer at $\mathrm{pH}$ 5.0. The MonoS column was eluted with $50 \mathrm{ml}$ of a 0 to $0.5 \mathrm{M} \mathrm{NaCl}$ gradient. Fractions of $0.75 \mathrm{ml}$ were collected and assayed for PME activity. The most active MonoS fraction was analyzed by analytical IEF on a $0.8 \mathrm{~mm}$ thick PAA gel containing $1.6 \%$ (vol/vol) of carrier ampholytes covering the $\mathrm{pH}$ ranges 3 to 10 (GE Healthcare) or 8.0 to 10.5 (Sigma-Aldrich). After staining with Coomassie blue, the only visible protein band was excised from the gel and was subjected to tryptic digestion prior to LC-MS/MS identification. Protein digestion and identification were performed by S. Tolin at the Centre for Research on Proteomics of Padua University.

\section{PME activity assay.}

The PME activity was analyzed using a cup-plate agar diffusion assay. A gel was prepared with $0.1 \%$ (wt/vol) apple pectin (approximately $72 \%$ esterified) and $1 \%$ (wt/vol) agarose in McIlvaine's buffer (25 mM citric acid and $115 \mathrm{mM}$ $\mathrm{Na}_{2} \mathrm{HPO}_{4}, \mathrm{pH}$ 6.0). The gel was poured into petri dishes $(12 \mathrm{ml}$ per plate) and $6 \mathrm{~mm}$ diameter wells were made in each plate. The samples were then loaded into each well and plates were incubated at $30^{\circ} \mathrm{C}$ for $16 \mathrm{~h}$. Plates were stained with $0.02 \%$ (wt/vol) ruthenium red for $45 \mathrm{~min}$ and were then washed with water to remove unbound dye. The formation of a red halo around the wells indicated the de-esterification of pectin and the presence of PME activity. A $0.5-\mathrm{cm}$ radius halo was defined as one agarose diffusion unit.

PME activity was also analyzed after an analytical IEF run by blotting the PAA gel, containing $1.6 \%$ (vol/vol) carrier ampholytes, covering the $\mathrm{pH}$ range 3 to 10 (GE Healthcare) or 8.0 to 10.5 (Sigma-Aldrich), on a $15-\mathrm{ml}$ overlay gel containing McIlvaine's buffer, $0.05 \%$ (wt/vol) pectin from apple $(72 \%$ esterification) and $1 \%(\mathrm{wt} / \mathrm{vol})$ agarose at $\mathrm{pH} 6.0$ (pectin gel blot assay). After incubating $45 \mathrm{~min}$ at $30^{\circ} \mathrm{C}$, the blotted agarose gel was stained with $0.05 \%(\mathrm{wt} / \mathrm{vol})$ ruthenium red.

\section{PG activity assays on highly methylated pectin.}

The culture filtrates of $F$. graminearum WT and $\Delta$ pme mutant strains grown on Szécsi medium supplemented with $1 \%(\mathrm{wt} / \mathrm{vol}$ ) apple pectin (approximately $72 \%$ of methyl esterification) were assayed for PG activity by the reducing-end groups method described by Milner and Avigad (1967) with some modifications (Sella et al. 2004). Briefly, $4 \mu$ of the culture filtrates were incubated for $30 \mathrm{~min}$ at $30^{\circ} \mathrm{C}$ in a $200-\mu \mathrm{l}$ reaction mixture containing PGA (85\% titration) (SigmaAldrich) dissolved at a concentration of $0.5 \%$ (wt/vol) in $50 \mathrm{mM}$ sodium acetate buffer at $\mathrm{pH}$ 6.0, which was determined to be the optimal $\mathrm{pH}$ for $F$. graminearum $\mathrm{PG}$ activity (Tomassini et al. 2009).

One reducing unit (RU) was defined as the amount of en-

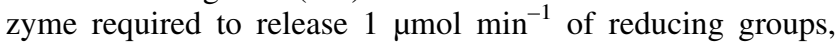
using D-galacturonic acid as the standard. An equal amount of PG activity (0.005 RU) from each culture was then assayed on $0.1 \%$ (wt/vol) PGA or $0.1 \%$ (wt/vol) apple pectin (approximately 38 or $72 \%$ esterification) buffered at $\mathrm{pH} 6.0$. After $24 \mathrm{~h}$ of incubation at $30^{\circ} \mathrm{C}$, reducing-end groups were measured as reported above and the hydrolysis percentage of each substrate was calculated.

The activity of the main $F$. graminearum $\mathrm{PG}$, named PG1 and purified as previously reported, (Tomassini et al. 2009), was determined on apple pectin having different esterification degrees (approximately 8, 38, and 72\%) using the viscosimetric method in the presence or absence of the purified fungal PME. Viscosimetric activity was assayed by measuring the decrease in relative viscosity at $30^{\circ} \mathrm{C}$ of a $2-\mathrm{ml}$ reaction mixture 
containing $0.5 \%(\mathrm{wt} / \mathrm{vol})$ pectin substrate dissolved in $50 \mathrm{mM}$ sodium acetate buffer ( $\mathrm{pH}$ 6.0) supplemented with $0.1 \mathrm{mg}$ of bovine serum albumin per milliliter, and 40 viscosimetric units (VU) of PG1 activity with or without 1.4 agarose diffusion units of PME activity. One VU, determined on $0.5 \%$ (wt/vol) PGA, was defined as the amount of enzyme causing a 50\% decrease in the initial viscosity of the reaction mixture at $\mathrm{pH} 6.0$ in 1,000 minutes. Micro-Ostwald capillary viscosimeters (i.d. $=$ $0.70 \mathrm{~nm}$ ) connected to an AVS 310 system (Schott Geräte, Mainz, Germany) were used. The time employed by the enzyme to decrease the initial relative viscosity of the reaction mixture by $50 \%$ was defined as $\mathrm{T}_{50}$ (expressed in seconds).

\section{Growth and infection of wheat plants.}

Wheat seeds of T. aestivum cv. Bobwhite and T. durum cv. Svevo were surface-sterilized by immersion in sodium hypochlorite $(0.5 \% \mathrm{vol} / \mathrm{vol})$ for $10 \mathrm{~min}$, were rinsed thoroughly in sterile water, and were incubated for 3 days in the dark on wet filter paper for germination. Seedlings were then vernalized at $4^{\circ} \mathrm{C}$ for 7 to 10 days before transplanting in soil. Plants were grown in a climatic chamber with a 14 -h photoperiod and $19^{\circ} \mathrm{C}$ day and $17^{\circ} \mathrm{C}$ night temperatures for approximately one month, with a 14 -h photoperiod and $22^{\circ} \mathrm{C}$ day and $20^{\circ} \mathrm{C}$ night temperatures until anthesis.

Wheat spike infections were performed by inoculating single spikelets at anthesis (Zadoks stage 65-67) (Zadoks et al. 1974) with $F$. graminearum WT or mutant strains. Spikes were inoculated by pipetting $10 \mu \mathrm{l}$ of a fresh conidial suspension containing approximately 2,000 conidia for cv. Bobwhite or 500 conidia for $\mathrm{cv}$. Svevo between the glumes of two florets of two opposite central spikelets. At least three independent experiments were performed by inoculating at least 10 plants with each strain. After inoculation, spikes were covered for 3 days with a plastic bag to maintain a moist environment. Plants were then moved to a growth chamber with $85 \%$ relative humidity under a 14-h photoperiod and at $22^{\circ} \mathrm{C}$ day and $20^{\circ} \mathrm{C}$ night temperatures. Disease symptoms were assessed by counting the number of visually diseased spikelets at different days and by relating them to the total number of spikelets of the respective head, resulting in a percentage of symptomatic spikelets. Data were statistically analyzed by applying the two-tailed Student's $t$ test or Tukey-Kramer's test.

\section{Nucleic acid extraction.}

Genomic DNAs of $F$. graminearum WT and mutant strains were extracted from 200 to $400 \mathrm{mg}$ of mycelium obtained in complete medium liquid culture as reported by Henrion et al. (1994).

RNA was extracted from $100 \mathrm{mg}$ of frozen wheat spikes infected with $F$. graminearum at $0,1,2,3$, and 4 dpi, using the RNeasy plant mini kit (Qiagen $\mathrm{GmbH}$, Milano, Italy) following the manufacturer's instructions. RNA was then treated with DNaseI (Promega, Milano, Italy) following the manufacturer's instructions and was quantified both spectrophotometrically and by a denaturing $1 \%$ (wt/vol) agarose gel.

\section{Construction of the gene replacement vector and fungal transformation-mediated gene disruption.}

The disruption of the F. graminearum Pmel gene (Munich Information Center for Protein Sequences database entry FGSG_03406) was obtained by targeted homologous recombination. To generate the disruption construct, a fragment of 1,701 bp containing $798 \mathrm{bp}$ of the coding region and $903 \mathrm{bp}$ of a downstream region was obtained by PCR, using specific oligonucleotides fg03406-5int (5'ACAGCGAAGAAGAGCCAAGCAGAT-3') and fg03406-3downnested (5'-TATGTTGATGGGCGATTAT TGTC- $3^{\prime}$ ). All of the primers were designed using the DNAMAN
(Lynnon Biosoft) program. The amplification was performed using the REDTaq ReadyMix PCR reaction mix (SigmaAldrich) in a 50- $\mu$ l volume. The PCR conditions were $94^{\circ} \mathrm{C}$ for $3 \mathrm{~min}$, followed by 35 cycles at $94^{\circ} \mathrm{C}$ for $30 \mathrm{~s}, 52.5^{\circ} \mathrm{C}$ for $30 \mathrm{~s}$, and $72^{\circ} \mathrm{C}$ for $1 \mathrm{~min}$. The amplicon obtained was cut from an agarose gel and was purified and cloned into the pGEM-T Easy vector (Promega), following the manufacturer's instructions. An Escherichia coli colony correctly transformed with the recombinant vector was grown in a lysogeny broth high-salt culture (Sigma-Aldrich). After an overnight incubation at $37^{\circ} \mathrm{C}$, the plasmid DNA was extracted and purified according to the MIDI Nucleobond Ax kit (Macherey-Nagel GmbH \& Co., Milano, Italy) manual. The recombinant plasmid was then cleaved with Eco47III and EcoNI (Promega) to remove $210 \mathrm{bp}$ of the FgPmel coding sequence. The DNA fragment containing the vector and the two flanking regions was then separated from the 210-bp fragment on a 1\% (wt/vol) agarose gel and was cut and purified using the Wizard SV Gel and PCR cleanup system (Promega). The hygromycin-resistance gene $h p h$ (hygromycin B phosphotransferase), used as a selective marker (Punt et al. 1987), was then amplified using specific oligonucleotides containing adaptors with Eco47III and EcoNI recognition site sequences (Hyg-Eco47IIIUP: 5'-GAGCGCTGACAGCTCTTGTTCGGTCG-3' and HygEcoNIDOWN: 5'-GCCTTCGACAGGAGCGAGGTGGGT GATGTAG-3') and the pAN7-1 vector (Voigt et al. 2005) containing the $h p h$ gene with regulatory sequences as the template. The amplification was performed with the REDTaq ReadyMix PCR reaction mix (Sigma-Aldrich) in a 50- $\mu$ l volume. The PCR conditions were $94^{\circ} \mathrm{C}$ for $3 \mathrm{~min}$, followed by 35 cycles at $94^{\circ} \mathrm{C}$ for $30 \mathrm{~s}, 58^{\circ} \mathrm{C}$ for $30 \mathrm{~s}$, and $72^{\circ} \mathrm{C}$ for $1 \mathrm{~min}$. The amplicon of the expected size (approximately 1,800 bp) was

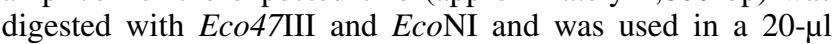
ligase reaction containing the previously cleaved recombinant plasmid, which contained the homologous flanking regions of the pme gene, $1 \times$ ligation buffer and $1 \mu \mathrm{l}$ of T4 DNA ligase (Promega). The final recombinant plasmid obtained after ligation, named pGEM- $\triangle \mathrm{PME}$, contained the hygromycinresistance gene between the upstream and downstream flanking sequences, approximately 600 and $900 \mathrm{bp}$, respectively, of the F. graminearum Fgpmel gene.

To obtain enough of the construct for transformation, an E. coli colony transformed with the pGEM- $\triangle \mathrm{PME}$ vector was grown in a lysogeny broth high-salt culture (Sigma-Aldrich). After an overnight incubation at $37^{\circ} \mathrm{C}$, the plasmid DNA was extracted according to the MIDI Nucleobond Ax kit (MachereyNagel GmbH \& Co.) manual and the construct (approximately $3.2 \mathrm{kbp}$ ) was cleaved from the pGEM-T vector using ApaI and SalI (Promega) and was used to transform protoplasts of the F. graminearum WT strain. Protoplastation and transformation were performed as reported by Nguyen et al. (2012).

The hygromycin-resistant mutants obtained underwent single conidiation and were screened using PCR with the specific primers Fg3406-INTF1 and Fg3406-INTR1 (Table 3), the REDTaq ReadyMix PCR reaction mix and the following PCR conditions: $94^{\circ} \mathrm{C}$ for $3 \mathrm{~min}$, then 35 cycles at $94^{\circ} \mathrm{C}$ for $30 \mathrm{~s}, 50^{\circ} \mathrm{C}$ for $30 \mathrm{~s}$, and $72^{\circ} \mathrm{C}$ for $30 \mathrm{~s}$. Transformants having a deleted fragment of the FgPmel gene were then tested by Southern blot hybridization.

\section{Complementation of the $\Delta$ pme mutant.}

Complementation of the $\Delta$ pme mutant was performed by cotransforming protoplasts of the $\Delta$ pme 1.2 mutant strain with the entire pme gene, which was flanked by the native promoter and terminator sequences, and with the selective marker $n p t I I$, which encodes geneticin resistance under control of the gpdA promoter (Ilgen et al. 2009), excised from the pII99 vector with 
BglII and HindIII (Promega). The pme gene with promoter and terminator regions $(3,174 \mathrm{bp})$ was amplified using PCR from the $F$. graminearum WT strain 3827 . The amplification was performed in a 50- $\mu$ l volume using the REDTaq ReadyMix PCR reaction mix and the primers 03406-5nest (5'-CGCTCTG CTCTGTTAGTATTTC-3') and 03406-3nest (5'-AGCGGGA CAGCTATCAGTTA-3'). PCR conditions were $94^{\circ} \mathrm{C}$ for $3 \mathrm{~min}$, followed by 35 cycles at $94^{\circ} \mathrm{C}$ for $30 \mathrm{~s}, 52^{\circ} \mathrm{C}$ for $30 \mathrm{~s}$, and $72^{\circ} \mathrm{C}$ for $4 \mathrm{~min}$.

The amplicon was cloned into pGEM-T Easy, was excised with SalI and SacII (Promega), and was then used for cotransformation. The transformants obtained were screened for the presence of pme and nptII genes by PCR and Southern blot analysis (Table 3 ).

\section{Southern blot analysis.}

For the Southern blot analysis, approximately 5 to $7 \mu \mathrm{g}$ of genomic DNA was digested with ClaI (for screening knockout mutants) (Promega) or with EcoRV and PstI (for screening complemented strains) (Thermo Scientific, Milano, Italy), was separated on a $1.0 \%$ (wt/vol) agarose gel, and was blotted onto a Hybond NX membrane (Amersham Biosciences, Milano, Italy). Digoxygenin (DIG)-labeled (Roche, Mannheim, Germany) specific probes were generated, using PCR with specific primers and genomic or plasmid DNA as the template (Table 3), and were used for overnight hybridizations at $65^{\circ} \mathrm{C}$. The PCR reaction was performed in a 50- $\mu$ l volume using DIG-11-dUTP (Roche). PCR conditions consisted of an initial step at $94^{\circ} \mathrm{C}$ for $2 \mathrm{~min}$, followed by 35 cycles of $94^{\circ} \mathrm{C}$ for $1 \mathrm{~min}$, a suitable annealing temperature (Table 3) for $1 \mathrm{~min}$, and $72^{\circ} \mathrm{C}$ for $2 \mathrm{~min}$.

Southern hybridization and detection of the DIG-labeled probes were performed according to manufacturer's instructions. The membranes were exposed to X-ray film (X-Omat AR, Kodak, Rochester, NY, U.S.A.) for approximately $3 \mathrm{~h}$.

Digestion with $\mathrm{Cla}$ I produced a $1.8-\mathrm{kb}$ fragment in the WT that hybridized with the Fgpmel probe and a fragment of $3.3 \mathrm{~kb}$ in the mutant strains that hybridized with the hygromycin probe in cases of homologous construct integration. Digestion with EcoRV and PstI produced an 8.4-kb fragment in the WT that hybridized with the Fgpme1 probe.

\section{FgPme1 expression in planta.}

For the reverse transcription (RT) reaction, $0.5 \mu \mathrm{g}$ of an oligo-dT (15/18 thymine) reverse primer was mixed with approximately $1 \mu \mathrm{g}$ of the target RNA in a total volume of $10 \mu \mathrm{l}$. After incubation at $70^{\circ} \mathrm{C}$ for $5 \mathrm{~min}$ and then at $4{ }^{\circ} \mathrm{C}$ for $5 \mathrm{~min}$, the mixture was added to a solution containing $1 \times$ ImPromII buffer (Promega), $1 \mathrm{mM}$ of each dNTP, $\mathrm{MgCl}_{2}$ to a final concentration of $3 \mathrm{mM}, 1 \mu \mathrm{l}$ ImPromII RT (Promega), and water to a final volume of $30 \mu \mathrm{l}$. The RT was carried out in a thermal cycler with the following cycle: $5 \mathrm{~min}$ at $25^{\circ} \mathrm{C}, 60 \mathrm{~min}$ at $42^{\circ} \mathrm{C}$, and $15 \mathrm{~min}$ at $70^{\circ} \mathrm{C}$.

The amplification of FgPmel and the F. graminearum $\beta$-tubulin reference gene (accession number FGSG_06611) were performed by real time PCR (Rotor-Gene Q 2plex; Qiagen $\mathrm{GmbH}$ ) using

Table 3. Nucleotide sequences of primers used to screen knockout and complemented mutants and to amplify the labeled probes for Southern blot analysis

\begin{tabular}{llc}
\hline Primer name & \multicolumn{1}{c}{ Sequence } & T $_{\mathbf{a}}$; product size $^{\mathbf{a}}$ \\
\hline Fg3406-INTF1 & CCAGAAGACCAGCATGAG & \\
Fg3406-INTR1 & CCTCCTTCGACAGGTGAT & $50^{\circ} \mathrm{C} ; 250 \mathrm{bp}$ \\
HygPRBf & AAAGTGCCGATAAACATAAC & \\
HygPRBr & AGAGTGATGCTTTGAGAGAG & $55^{\circ} \mathrm{C} ; 475 \mathrm{bp}$ \\
GenPRBf & AGGATCTCCTGTCATCTCA & \\
GenPRBr & CCAAGCTCTTCAGCAATA & $55^{\circ} \mathrm{C} ; 400 \mathrm{bp}$ \\
\hline
\end{tabular}

${ }^{\mathrm{a}} \mathrm{T}_{\mathrm{a}}=$ annealing temperature. specific primers (fg03406-5int: 5'-ACAGCGAAGAAGAGCCA AGCAGAT-3'; fg03406-3int: 5'-CTCCAGGGTCGGCCAAGG TAGTAG-3'; BetatubF: 5'-CCCAACAACGTCCAAACTTCC-3'; BetatubR: 5'-CCTCGGTGAATTCCATCTCGTC-3'). The 20- $\mu 1$ reaction mixture contained $10 \mu \mathrm{l}$ of $2 \times$ Brilliant III Ultra-Fast SYBR green QPCR mastermix (Agilent Technologies, Milano, Italy), $0.4 \mu \mathrm{M}$ of each specific primer and $3 \mu \mathrm{l}$ of cDNA as the template.

The real time quantitative (q)PCR was performed using 40 cycles of the following: $15 \mathrm{~s}$ at $95^{\circ} \mathrm{C}, 15 \mathrm{~s}$ at $56^{\circ} \mathrm{C}$, and $40 \mathrm{~s}$ at $72^{\circ} \mathrm{C}$. Relative expression levels were analyzed using the Rotor-Gene 2.0.3.2 Software version (Qiagen $\mathrm{GmbH}$ ). Three independent qPCR experiments were performed.

\section{ACKNOWLEDGMENTS}

We thank S. Odorizzi of Padova University for the excellent technical assistance and Consorzio Interuniversitario Biotecnologie (CIB) for funding the research stage of M. C. Paccanaro at the Biocenter Klein Flottbek of Hamburg University. Research was supported by Padova University (Progetto di Ateneo 2010, prot. CPDA109182) to L. Sella, by the Italian Ministry of University and Research and the Deutscher Akademischer Austauschdienst (Programma Vigoni 2009-2011) to F. Favaron and W. Schäfer, and by the Italian Ministry of University and Research (PRIN 2010-2011) to R. D’Ovidio.

\section{LITERATURE CITED}

Bai, G. H., Desjardins, A. E., and Plattner, R. D. 2002. Deoxynivalenolnonproducing Fusarium graminearum causes initial infection, but does not cause disease spread in wheat spikes. Mycopathologia 153:91-98.

Cappellini, R. A., and Peterson, J. L. 1965. Macroconidium formation in submerged culture by a nonsporulating strain of Gibberella zeae. Mycologia 57:962-966.

Chateigner-Boutin, A.-L., Bouchet, B., Alvarado, C., Bakan, B., and Guillon, F. 2014. The wheat grain contains pectic domains exhibiting specific spatial and development-associated distribution. PLoS One 9:e89620.

Clay, R. P., Bergmann, C. W., and Fuller, M. S. 1997. Isolation and characterization of an endopolygalacturonase from Cochliobolus sativus and a cytological study of fungal penetration of barley. Phytopathology 87: 1148-1159.

Di Pietro, A., and Roncero, M. I. G. 1998. Cloning, expression, and role in pathogenicity of $p g 1$ encoding the major extracellular endopolygalacturonase of the vascular wilt pathogen Fusarium oxysporum. Mol. PlantMicrobe Interact 11:91-98.

Ferrari, S., Sella, L., Janni, M., De Lorenzo, G., Favaron, F., and D’Ovidio, R. 2012. Transgenic expression of polygalacturonase-inhibiting proteins in Arabidopsis and wheat increases resistance to the flower pathogen Fusarium graminearum. Plant Biol Stuttg 14 (Suppl 1): 31-38.

Gao, S., Choi, G. H., Shain, L., and Nuss, D. L. 1996. Cloning and targeted disruption of enpg-1, encoding the major in vitro extracellular endopolygalacturonase of the chestnut blight fungus, Cryphonectria parasitica. Appl. Environ. Microbiol. 62:1984-1990.

Goswami, R. S., and Kistler, H. C. 2004. Heading for disaster: Fusarium graminearum on cereal crops. Mol. Plant Pathol. 5:515-525.

Güldener, U., Seong, K.-Y., Boddu, J., Cho, S., Trail, F., Xu, J.-R., Adam, G., Mewes, H.-W., Muehlbauer, G. J., and Kistler, H. C. 2006 Development of a Fusarium graminearum Affymetrix GeneChip for profiling fungal gene expression in vitro and in planta. Fungal Genet. Biol. 43:316-325.

Henrion, B., Chevalier, G., and Martin, F. 1994. Typing truffle species by PCR amplification of the ribosomal DNA spacers. Mycol. Res. 98:37-43.

Ilgen, P., Hadeler, B., Maier, F. J., and Schäfer, W. 2009. Developing kernel and rachis node induce the trichothecene pathway of Fusarium graminearum during wheat head infection. Mol. Plant-Microbe Interact 22:899-908.

Isshiki, A., Akimitsu, K., Yamamoto, M., and Yamamoto, H. 2001. Endopolygalacturonase is essential for citrus black rot caused by Alternaria citri but not brown spot caused by Alternaria alternata. Mol. Plant-Microbe Interact 14:749-757.

Jolie, R. P., Duvetter, T., Van Loey, A. M., and Hendrickx, M. E. 2010. Pectin methylesterase and its proteinaceous inhibitor: A review. Carbohydr. Res. 345:2583-2595. 
Kang, Z., and Buchenauer, H. 2000a. Ultrastructural and cytochemical studies on cellulose, xylan and pectin degradation in wheat spikes infected by Fusarium culmorum. J. Phytopathol. 148:263-275.

Kang, Z., and Buchenauer, H. 2000b. Ultrastructural and immunocytochemical investigation of pathogen development and host responses in resistant and susceptible wheat spikes infected by Fusarium culmorum. Physiol. Mol. Plant Pathol. 57:255-268.

Kars, I., McCalman, M., Wagemakers, L., and VAN Kan, J. A. L. 2005. Functional analysis of Botrytis cinerea pectin methylesterase genes by PCR-based targeted mutagenesis: Bcpme1 and Bcpme 2 are dispensable for virulence of strain B05.10. Mol. Plant Pathol. 6:641-652.

Kikot, G. E., Hours, R. A., and Alconada, T. M. 2009. Contribution of cell wall degrading enzymes to pathogenesis of Fusarium graminearum: A review. J. Basic Microbiol. 49:231-241.

Lysøe, E., Seong, K. Y., and Kistler, H. C. 2011. The transcriptome of Fusarium graminearum during the infection of wheat. Mol. PlantMicrobe Interact 24:995-1000.

Malinovsky, F. G., Fangel, J. U., and Willats, W. G. T. 2014. The role of the cell wall in plant immunity. Front. Plant Sci. 5:178.

McMullen, M., Jones, R., and Gallemberg, D. 1997. Scab of wheat and barley: A remerging disease of devastating impact. Plant Dis. 81:1340-1348.

Miller, S. A., Chabot, D. M. P., Oullet, T., Harris, L. J., and Fedak, G. 2004. Use of a Fusarium graminearum strain transformed with green fluorescent protein to study infection in wheat (Triticum aestivum). Can. J. Plant Pathol. 26:453-463.

Milner, Y., and Avigad, G. 1967. A copper reagent for the determination of hexuronic acids and certain ketohexoses. Carbohydr. Res. 4:359-361.

Nguyen, V. N., Schäfer, W., and Bormann, J. 2012. The stress-activated protein kinase FgOS-2 is a key regulator in the life cycle of the cereal pathogen Fusarium graminearum. Mol. Plant-Microbe Interact 25:11421156.

Oeser, B., Heidrich, P. M., Müller, U., Tudzynski, P., and Tenberge, K. B. 2002. Polygalacturonase is a pathogenicity factor in the Claviceps purpurea/rye interaction. Fungal Genet. Biol. 36:176-186.

Paper, J. M., Scott-Craig, J. S., Adhikari, N. D., Cuomo, C. A., and Walton, J. D. 2007. Comparative proteomics of extracellular proteins in vitro and in planta from the pathogenic fungus Fusarium graminearum. Proteomics 7:3171-3183

Pritsch, C., Muehlbauer, G. J., Bushnell, W. R., Somers, D. A., and Vance, C. P. 2000. Fungal development and induction of defense response genes during early infection of wheat spikes by Fusarium graminearum. Mol. Plant-Microbe Interact 13:159-169.

Punt, P. J., Oliver, R. P., Dingemanse, M. A., Pouwels, P. H., and van den Hondel, C. A. 1987. Transformation of Aspergillus based on the hygromycin B resistance marker from Escherichia coli. Gene 56:117-124.

Scott-Craig, J. S., Cheng, Y. Q., Cervone, F., De Lorenzo, G., Pitkin, J. W., and Walton, J. D. 1998. Targeted mutants of Cochliobolus carbonum lacking the two major extracellular polygalacturonases. Appl. Environ. Microbiol. 64:1497-1503.

Sella, L., Castiglioni, C., Roberti, S., D’Ovidio, R., and Favaron, F. 2004. An endo-polygalacturonase (PG) of Fusarium moniliforme escaping inhibition by plant polygalacturonase-inhibiting proteins (PGIPs) provides new insights into the PG-PGIP interaction. FEMS (Fed. Eur. Microbiol. Soc.) Microbiol. Lett. 240:117-124.

Sella, L., Tomassini, A., D'Ovidio, R., and Favaron, F. 2005. Expression of two Sclerotinia sclerotiorum endo-pg genes correlates with endopolygalacturonase activity during Glycine max infection. J. Plant Pathol. 87:199-205.
Shieh, M. T., Brown, R. L., Whitehead, M. P., Cary, J. W., Cotty, P. J., Cleveland, T. E., and Dean, R. A. 1997. Molecular genetic evidence for the involvement of a specific polygalacturonase, $\mathrm{P} 2 \mathrm{c}$, in the invasion and spread of Aspergillus flavus in cotton bolls. Appl. Environ. Microbiol. 63:3548-3552.

Szécsi, A. 1990. Analysis of pectic enzyme zymograms of Fusarium species. II. Comparison of polygalacturonase zymograms of Fusarium culmorum and Fusarium graminearum. J. Phytopathol. 130:188-196.

ten Have, A., Mulder, W., Visser, J., and van Kan, J. A. L. 1998. The endopolygalacturonase gene Bcpgl is required for full virulence of Botrytis cinerea. Mol. Plant-Microbe Interact 11:1009-1016.

ten Have, A., Tenberge, K. B., Benen, J. A. E., Tudzynski, P., Visser, J., and van Kan, J. A. L. 2002. The contribution of cell wall degrading enzymes to pathogenesis of fungal plant pathogens. Pages 341-358 in: Agricultural Applications, The Mycota Volume 11. F. Kempken, ed., Springer-Verlag, Berlin.

Tenberge, K. B., Homann, V., Oeser, B., and Tudzynski, P. 1996. Structure and expression of two polygalacturonase genes of Claviceps purpurea oriented in tandem and cytological evidence for pectinolytic enzyme activity during infection of rye. Phytopathology 86:1084-1097.

Tomassini, A., Sella, L., Raiola, A., D’Ovidio, R., and Favaron, F. 2009. Characterization and expression of Fusarium graminearum endopolygalacturonases in vitro and during wheat infection. Plant Pathol. 58:556-564.

Urban, M., Daniels, S., Mott, E., and Hammond-Kosack, K. 2002. Arabidopsis is susceptible to the cereal ear blight fungal pathogens Fusarium graminearum and Fusarium culmorum. Plant J. 32:961-973.

Valette-Collet, O., Cimerman, A., Reignault, P., Levis, C., and Boccara, M. 2003. Disruption of Botrytis cinerea pectin methylesterase gene Bcpme1 reduces virulence on several host plants. Mol. Plant-Microbe Interact 16:360-367.

Vogel, J. 2008. Unique aspects of the grass cell wall. Curr. Opin. Plant Biol. 11:301-307.

Voigt, C. A., Schäfer, W., and Salomon, S. 2005. A secreted lipase of Fusarium graminearum is a virulence factor required for infection of cereals. Plant J. 42:364-375.

Volpi, C., Janni, M., Lionetti, V., Bellincampi, D., Favaron, F., and D'Ovidio, R. 2011. The ectopic expression of a pectin methyl esterase inhibitor increases pectin methyl esterification and limits fungal diseases in wheat. Mol. Plant-Microbe Interact 24:1012-1019.

Wanjiru, W. M., Zhensheng, K., and Buchenauer, H. 2002. Importance of cell wall degrading enzymes produced by Fusarium graminearum during infection of wheat heads. Eur. J. Plant Pathol. 108:803-810.

Wiethölter, N., Graessner, B., Mierau, M., Mort, A. J., and Moerschbacher, B. M. 2003. Differences in the methyl ester distribution of homogalacturonans from near-isogenic wheat lines resistant and susceptible to the wheat stem rust fungus. Mol. Plant-Microbe Interact 16:945952.

Zadoks, J. C., Chang, T. T., and Konzak, C. F. 1974. A decimal code for the growth of cereals. Weed Res. 14:415-421.

\section{AUTHOR-RECOMMENDED INTERNET RESOURCES}

Broad Institute Fusarium Comparative database:

http://www.broadinstitute.org/annotation/genome/fusarium_graminearum Institute of Bioinformatics and Systems Biology Fungal and Microbial Genomics database: http://mips.helmholtz-muenchen.de/genre/proj/FGDB 